\title{
Knowledge, politics and power in global health Comment on "Knowledge, moral claims and the exercise of power in global health"
}

\section{Garrett Wallace Brown ${ }^{*}$}

\section{Abstract}

This article agrees with recent arguments suggesting that normative and epistemic power is rife within global health policy and provides further examples of such. However, in doing so, it is argued that it is equally important to recognize that global health is, and always will be, deeply political and that some form of power is not only necessary for the system to advance, but also to try and control the ways in which power within that system operates. In this regard, a better focus on health politics can both expose illegitimate sources of power, but also provide better recommendations to facilitate deliberations that can, although imperfectly, help legitimate sources of influence and power.

Keywords: Global Health, Power, Politics of Health

Copyright: ๑ 2015 by Kerman University of Medical Sciences

Citation: Brown GW. Knowledge, politics and power in global health: Comment on "Knowledge, moral claims and the exercise of power in global health". Int J Health Policy Manag 2015; 4: 111-113. doi: $10.15171 /$ ijhpm.2015.20
Article History:

Received: 18 January 2015 Accepted: 30 January 2015 ePublished: 30 January 2015
$\mathrm{F}$ rancis Bacon coined the aphorism "ipsa scientia potestas est", which can be roughly translated as "knowledge is power" (1). Yet, what exactly this often quoted aphorism means remains an issue of debate. For example, the aphorism is often understood in Hobbesian terms (2) as having possession of knowledge above others for asymmetric gain. Or it can be viewed more in line with Bacon's own vision, as representing an acceptance of God's omnipotence (3). Moreover, the aphorism can reflect Emerson's view (3), where the gaining of knowledge provides one with the power to master oneself as well as nature. Lastly, we can understand the idea that knowledge is power in post-structural or Nietzschean terms (4), whereby producing claims of "knowledge" is itself an act of imposing power, where language embeds power and potential domination. What is common in all of these renderings is that claims to knowledge represent claims to objective "truth" and that understanding (or producing) this truth provides the ability to have superior influence and to increase measurable and relational success, be it personal, social or otherworldly.

In his recent editorial, Jeremy Shiffman argues that the policy domain of global health is deeply imbrued with normative and epistemic forms of power and that the idea of "knowledge is power" often remains unnoticed, ignored or undervalued within contemporary global health policy debates (5). As Shiffman illustrates, competing claims to authoritative knowledge underwrites existing leadership struggles between the World Health Organization (WHO) and the Institute for Health Metrics and Evaluation (IHME) and are rife within policy debates associated with the Millennium Development Goals and their shift to a "sustainable" post2015 agenda. Furthermore, less obvious forms of power can be found in other sources of knowledge production. For example, whereas the World Bank is often mocked for its selfdefinition as a "development knowledge bank", other claims to authoritative knowledge, such as those produced by the medical journal The Lancet, can also have profound influence upon policy agendas and debates, thus representing a form of unrecognized epistemic power.

As Shiffman rightly highlights, the problem is that health scholars and policy-makers often fail to properly recognize the influence of normative and epistemic power, which allows certain ideas, institutions or policies to escape proper justificatory accountability mechanisms and scrutiny. Furthermore, by avoiding scrutiny, these forms of power are alternatively often assumed to be sources of legitimate authority. What is required, argues Shiffman, is a better awareness of power and sharper investigations into how these forms of power "get exercised in the global health field" and "under what circumstances they are justly derived" (5).

In many ways Shiffman's effort to expose the role of normative and epistemic power should be applauded and taken seriously. This is because the presence and exercise of these forms of power in global health policy are manifest. As one example, my research on Performance-Based Funding (PBF) in global health revealed the ideational dominance of PBF modalities at both the national and global levels (6). PBF was often assumed to be an effective funding mechanism for health system strengthening, despite inadequate evidence to support this view (7) and an inability by respondents to cite concrete evidence or reports (6). In line with Shiffman's concern, the research suggested that PBF has become ideationally structured in such a way that it represents "the only game in town" and thus closes off other potentially more suitable modalities for delivering funding. Although discussions about PBF do take place, it is mostly in regard to how to implement $\mathrm{PBF}$ and these discussions often exclude questions about the overall appropriateness of PBF as a long-term health reform tool itself. What this represents, à la Shiffman, is a form of structural and epistemic power that is reproduced through

Department of Politics, University of Sheffield, Sheffield, UK 
claims and assumptions of its reform effectiveness, despite a lack of concrete evidence, and despite growing evidence that suggests otherwise (7). As one African representative at the WHO lamented during interview, "I don't think there is a great deal of argument taking place about the risks of these types of funding mechanisms... on the whole donors and consultants are in favor of target-driven financing and they have successfully entrenched this as the primary mode of operation" (6).

Another example of normative and epistemic power concerns what is known as evidence-based policy and its explicit aim to "depoliticize" decision-making processes within global health policy. This aim for depoliticized policy has been championed by both the World Bank and The Global Fund to Fight AIDS, Malaria and Tuberculosis (TB), positing the view that policy decisions should be (a normative claim), and can be (an epistemic claim), free from value-based and political judgments so as to remove the influence of power and interest (8). This generates two concerns. First, this narrative presents evidence-based decisions in such a light as to presume the neutrality of "evidence". Yet, this seemingly ignores the obvious fact that value-based judgments are inherent to research production, since determinations regarding what sorts of evidence to gather, collate, review and advocate will need to be made and that these decisions will take place under conditions of finite research resources and within existing epistemologies (9). Second, as Barnes and Parkhurst have convincingly argued (10), the production of evidence-based policy is itself fundamentally going to have a political dimension, since governing procedures for the assigning of health priorities will factor into which issues are targeted, in determining who is most in need, what lines of evidence to accept as authoritative, in making determinations on how to apply this knowledge in practice, and in generating the political will or political capital necessary for policy to be effective.

In this regard, Shiffman's call for a better awareness of the role of power in global health is both timely and necessary, since examples of hard power, soft power, economic power, normative power, epistemic power, structural power and productive power are rampant in global health policy and governance (11). These are all forms of different kinds of power with different social-economic drivers and reproductive mechanisms. However, it must also be recognized that power is something that cannot be erased from the equation altogether and that the exercise of power itself is not always necessarily a bad thing.

First, as most political scientists will suggest, all social interactions involve elements of power. In any social environment it will be possible to locate implicit as well as explicit asymmetrical influence. This does not deny Shiffman's point that it is important to be critical of power, to expose it, and to mitigate against its more detrimental effects. What this simply confirms is that power will be part of any social arrangement and that any expectation that power can be fully harnessed is both naïve and normatively apolitical.

Second, normative and epistemic power is not always a bad thing. This is because there exist more justified and legitimate forms of power in global health and these forms of power can be used to restrict other forms of power. For example, it would be suspect to suggest that all forms of global norm diffusion regarding anti-AIDS stigmatization or the recommendation of male circumcision for reducing HIV/AIDS is necessarily a bad thing, since there are examples where these forms of normative and epistemic diffusions have had profoundly positive health effects. In addition, power is intimately bound to other potential normative and political goods, such as health justice, which itself refers to some egalitarian distribution of benefits and burdens and the legitimate use of coercion to fulfill these demands. What is demanded in the case of justice is the legitimation of power, not the removal of power altogether. And what legitimacy requires are reasonably acceptable political processes that can be deemed as "more just" under an "all affected principle" (12).

In many ways an appeal to more legitimate political processes captures Shiffman's overall conclusion, which seemingly suggests that rethinking the role of power is one method to better legitimate how power "is exercised in the global health field" and "under what circumstances [claims to knowledge and thus authority] are justly derived" (5). Yet, what needs to be added to Shiffman's assessment is the recognition that a better understanding of health politics and how power is politically exercised is also required. Although the role of politics has recently gained some key recognition from global health scholars (13-15), the study of global health politics is still hugely underdeveloped and its study mainly takes place by social scientists that operate at a distance from ongoing technical debates about health policy $(9,16)$. This is extremely troubling, since a focus on health politics can both expose illegitimate sources of power, but also provide better recommendations to facilitate deliberations that can, although imperfectly, help legitimate sources of influence and power (in whatever form). In other words, although Shiffman's call to recognize that "knowledge is power" is reflectively important, it is equally important to recognize that global health is, and always will be, deeply political and that some form of power is not only necessary for the system to advance, but also to try and control the ways in which that system operates. What is needed, I would suggest, is more analysis from the view that global health is a form of global politics beyond just technical medical evidence and the epistemic "truth" that much can be gleamed from understanding it as such.

Ethical issues

Not applicable.

\section{Competing interests}

Author declares that he has no competing interests.

Author's contribution

GWB is the single author of the manuscript.

\section{References}

1. Bacon F. Meditationes Sacrae. Whitefish: Kessinger Publications; 1996. p. 67.

2. Hobbes T. Leviathan. Indianapolis: Hackett Classics; 1994. Ch. 10.

3. Emerson R. Society and Solitude. Boston: The Riverside Press; 1892. p. 303.

4. Nietzsche F. The Will to Power: In Science, Nature, Society and Art. New York: Random House; 1968.

5. Shiffman J. Knowledge, moral claims and the exercise of power in global health. Int J Health Policy Manag 2014; 3: 297-9. doi: 
10.15171/ijhpm.2014.120

6. Barnes A, Brown GW, Harman S. The Global Politics of Health Reform in Africa: Performance, Participation and Policy. London: Palgrave; 2015.

7. Brown GW, Barnes A, Harman S, Gruia M, Papamichail A. Discussion Paper 98: Annotated literature review: Africa actors, global health governance and performance based funding. Equinet Africa. [cited Jan 19, 2015]. Available from: http://www. equinetafrica.org/bibl/docs/Diss \%2098\%20PBF\%20Lit\%20 Rev\%20June\%202013.pdf

8. BarnesA, Brown GW. The Global Fund to FightAIDS, Tuberculosis and Malaria: Expertise, accountability and the depoliticisation of global health. In: Rushton S, Williams O, editors. Partnerships and Foundations in Global Health Governance. Basingstoke: Palgrave; 2011. p. 53-75.

9. Ooms G. From international health to global health: How to foster a better dialogue between empirical and normative disciplines. BMC Int Health Hum Rights 2014; 14: 36. doi: 10.1186/s12914014-0036-5

10. Barnes A, Parkhurst J. Can global health policy be depoliticized? A critique of global calls for evidence-based policy. In: Brown
GW, Yamey G, Wamala S, editors. Global Health Policy. London: Willey-Blackwell; 2014.

11. Marten R, Hanefeld J, Smith R. Power: The nexus of global health diplomacy Journal of Health Diplomacy 2014, 1 (2). [cited Jan. 29, 2015]. Available from: http://www.ghd-net.org/sites/ default/files/marten\%20hanefeld\%20smith_power\%20(1).pdf

12. Habermas J. Between Facts and Norms. Cambridge: Polity Press; 1996.

13. Bruen C, Brugha R. A ghost in the machine? Politics in global health policy. International Journal of Health Policy and Management 2014, 3: 1-4. doi: 10.15171/ijhpm.2014.59

14. McCoy D., \& Singh G., A Spanner in the works?: Anti-politics in global health policy. Int J Health Policy Manag 2014, 3: 151-3. doi: $10.15171 /$ ijhpm.2014.77

15. Hammer A. Democracy - The real 'ghost' in the machine of global health policy. Int J Health Policy Manag 2014; 3: 149-50. doi: 10.15171/ijhpm.2014.75

16. Kickbusch I, Lister G, Told M, Drager N. Global Health Diplomacy: Concepts, Issues, Actors, Instruments, Fora and Cases. London: Springer; 2013. 